\title{
Alcohol at bedtime induces minor changes in sleep stages and blood gases in stable chronic obstructive pulmonary disease
}

\author{
Nils Henrik Holmedahl • Britt Øverland • Ove Fondenes • \\ Ivar Ellingsen • Jon Andrew Hardie
}

Received: 26 February 2014 / Revised: 19 May 2014 / Accepted: 3 June 2014 / Published online: 17 June 2014

(C) The Author(s) 2014. This article is published with open access at Springerlink.com

\begin{abstract}
Purpose/background The purpose of this study is to explore the effect of a moderate dose of alcohol on sleep architecture and respiration in chronic obstructive pulmonary disease (COPD). Alcohol depresses both hypercapnic and hypoxic ventilatory drives in awake, normal individuals and reduces the amount of rapid eye movement (REM) sleep and oxygen saturation $\left(\mathrm{S}_{\mathrm{p}} \mathrm{O}_{2}\right)$ in sleeping COPD subjects.

Methods Prospectively designed, open-label interventional study in a pulmonary rehabilitation hospital. Twenty-six (nine males) stable inpatients, median forced expiratory volume first second (FEV1) $40.5 \%$ of predicted, median age 65 years, investigated by polysomnography including transcutaneous measurement of carbon dioxide pressure increase $\left(\Delta \mathrm{P}_{\mathrm{tc}} \mathrm{CO}_{2}\right)$ in randomized order of either control sleep or intervention with $0.5 \mathrm{~g}$ of ethanol/kilogram bodyweight, taken orally immediately before lights off.

Results Alcohol induced a mean increase $(95 \%$ confidence interval, [CI]) in the mean $\Delta \mathrm{P}_{\mathrm{tc}} \mathrm{CO}_{2}$ of $0.10 \mathrm{kPa}(0.002-0.206$,
\end{abstract}

Presentation at a conference: This material has not been presented at any conference.

Clinical trial registration number: NCT00888342

N. H. Holmedahl $(\bowtie) \cdot$ I. Ellingsen

LHL-klinikkene, Glittre, Glittreklinikken, postboks 104 Åneby,

1485 Hakadal, Norway

e-mail: nilshenrik.holmedahl@lhl-klinikkene.no

B. Øverland

ENT-Department, Lovisenberg Diakonale Hospital, Oslo, Norway

O. Fondenes

Norwegian National Centre of Excellence in Home Mechanical

Ventilation, Haukeland University Hospital, Bergen, Norway

N. H. Holmedahl • J. A. Hardie

Department of Clinical Science, University of Bergen, Bergen,

Norway
$P=0.047)$ and a mean decrease $(\mathrm{CI})$ in the REM-sleep percentage of total sleep time (REM \% of TST) of $3.1 \%(0.2-6.0),(P=0.020)$. Six subjects with apnea/ hypopnea index (AHI) $\geq 15$ had fewer apneas/hypopneas during alcohol versus control sleep (mean reduction of AHI 11 (1-20), $P=0.046$ ). Alcohol-sleep changes in $\mathrm{S}_{\mathrm{p}} \mathrm{O}_{2}$, but not in $\Delta \mathrm{P}_{\mathrm{tc}} \mathrm{CO}_{2}$, correlated with daytime arterial pressures of carbon dioxide $\left(\mathrm{P}_{\mathrm{a}} \mathrm{CO}_{2}\right)$ and oxygen $\left(\mathrm{P}_{\mathrm{a}} \mathrm{O}_{2}\right)$.

Conclusion Occasional use of a moderate, bedtime dose of alcohol has only minor respiratory depressant effects on the majority of COPD subjects, and in a minority even slightly improves respiration during sleep. However, caution is appropriate as this study is small and higher doses of alcohol may result in major respiratory depressive and additional negative health effects.

Keywords Ethanol - Transcutaneous blood gas monitoring · Hypoventilation $\cdot$ COPD $\cdot$ Carbon dioxide ·

Polysomnography

\section{Introduction}

Chronic obstructive pulmonary disease (COPD) has a significant morbidity and mortality [1], and chronic hypercapnic respiratory failure (CHRF) in COPD is associated with poor prognosis $[2,3]$. Heavy alcohol consumption has been shown to increase the risk of developing COPD [4-6]; on the other hand, mild alcohol intake may reduce the risk both of developing severe pulmonary function abnormalities and of dying from COPD [7, 8]. Sleep is characterized by periods of unstable respiration, and in normal, awake individuals, hypoxic and hypercapnic ventilatory drives are depressed by alcohol [9]. Sleep hypoventilation $(\mathrm{SH})$ has previously been shown to be frequent in severe COPD with CHRF and long-term oxygen therapy (LTOT) [10-12], and recently, we also found SH in 
some normocapnic, non-LTOT individuals with stable COPD [12]. Both in a study of 20 asymptomatic men aged 20 to 65 years [13] and in a study of 20 COPD subjects (19 men) [14], alcohol increased the number of sleep apneas. However, a study of 18 asymptomatic, postmenopausal women found no difference between placebo- and alcohol-influenced sleep in the number of episodes of apnea or hypopnea or in the frequency, length, or severity of oxygen desaturation [15]. In two small studies of four normal individuals and five subjects with stable COPD, alcohol taken immediately before sleep resulted in a moderately reduced mean $\mathrm{S}_{\mathrm{p}} \mathrm{O}_{2}$ and a reduced amount of rapid eye movement (REM) sleep [16, 17]. To our knowledge, no studies have explored alcohol-induced changes in carbon dioxide pressure $\left(\mathrm{PCO}_{2}\right)$ with polysomnography (PSG) in sleeping COPD patients. Concern is thus raised whether it is safe for individuals with COPD, especially those with CHRF or frequent apneas/hypopneas, to occasionally consume alcohol before sleep.

Hypothesizing an increase in the $\mathrm{PCO}_{2}$ during sleep, the primary aim of this study was to explore to what extent a moderate dose of alcohol prior to sleep induces hypoventilation in stable COPD patients, secondary whether apneas/hypopneas and sleep architecture is altered, and finally whether the alcohol-induced changes in blood gases during sleep is correlated to daytime COPD characteristics.

\section{Material and methods}

\section{Subjects}

Study participants were a randomized selection from the 166 subjects described in a previous article [12], all Caucasians with GOLD [18] defined COPD and inpatients at the Glittreklinikken Pulmonary Rehabilitation Hospital included from January 2010 through June 2011. The following exclusion criteria were used: diagnosed obstructive sleep apnea (OSA); COPD exacerbation within 3 weeks prior; other serious lung comorbidity (i.e., cancer, sarcoidosis, restrictive lung disease) or diseases affecting thoracic or abdominal movement, unstable angina pectoris, hypertension, diabetes mellitus, myocardial infarction within last 3 months, cerebral infarction, and addiction to drugs, alcohol, or narcotics. At inclusion, study subjects were randomized to receive alcohol, $5 \mathrm{mg}$ of Zopiclone (a sleep drug), or supplementary oxygen (data from the latter two interventions not yet published). All subjects used prescribed medication, but no drugs known to be respiratory depressants were taken from $48 \mathrm{~h}$ prior to first PSG recording until end of study. The protocol was approved by the Regional Ethics Committee in south-eastern Norway. As shown in Fig. 1, 26 pairs of PSG from control and alcoholinfluenced sleep were analyzed.

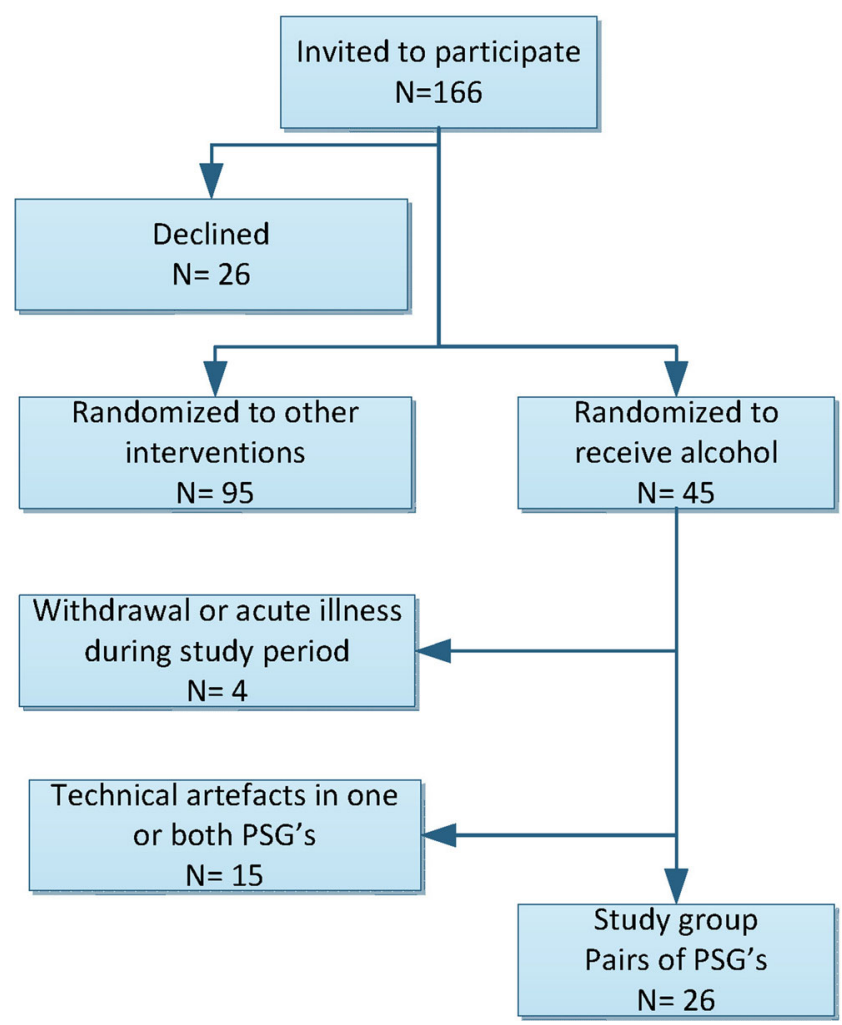

Fig. 1 Inclusion

Measurements

All subjects slept in their own bed at the hospital with full PSG for three nights; first night for acquaintance with the equipment, second and third nights randomized to either control or alcohol-influenced sleep. PSG was recorded online from Embla $\mathrm{A} 10^{1}$ with transcutaneously measured carbon dioxide pressure $\left(\mathrm{P}_{\mathrm{tc}} \mathrm{CO}_{2}\right)$ from Tosca $500^{2}$ to a bedside computer using Somnologica Studio Version 3.3 software. Channel setup was according to the 2007 recommendations from the American Academy of Sleep Medicine (AASM) [19]. PSGs were recorded only during weekdays. Alcohol $0.5 \mathrm{mg}$ per $\mathrm{kg}$ bodyweight (corresponding to about three glasses of wine in a $70-\mathrm{kg}$ person) was given as $96 \mathrm{vol} \%$ ethanol diluted in $200 \mathrm{ml}$ of orange juice and ingested the last $30 \mathrm{~min}$ prior to sleep [20]. Immediately before lights off, breath analysis by Lion alcometer $500^{3}$ was used to check that study-alcohol was taken.

Unpublished data collected at Glittreklinikken prior to the study showed equivalence between changes in $\mathrm{P}_{\mathrm{tc}} \mathrm{CO}_{2}$ and $\mathrm{P}_{\mathrm{a}} \mathrm{CO}_{2}$, but a delay time of 54-57 s. Details regarding delay time, $\mathrm{P}_{\mathrm{tc}} \mathrm{CO}_{2}$ signal stabilization, sampling frequency, and calculations according to sleep stages are given in our previous article [12].

\footnotetext{
${ }^{1}$ Medcare Flaga, Reykjavik, Iceland.

${ }^{2}$ Radiometer, Basel, Switzerland.

${ }^{3}$ Lion Laboratories Ltd., Vale of Glamorgan, UK.
} 
Arterial blood gas samples ${ }^{4}$ were collected after a 10 -min seated rest at approximately 2 p.m. prior to each PSG recording and analyzed within $10 \mathrm{~min}$ on the Radiometer ABL720Flex. ${ }^{5}$ At sampling, all subjects were breathing room air, with an exception for those on LTOT who used their prescribed dose of supplementary oxygen. Height, weight, and lung function tests including postbronchodilator spirometry, diffusing capacity (DLCO), and body plesmography of total lung volumes were recorded on MasterScreen Pneumo ${ }^{6}$ as previously described [12], reference values are based on equations from the European Community for Coal and Steel [21].

Sleep scoring was done by two experienced polysomnographists according to recommendations from the AASM [12, 19]; a hypopnea was scored when nasal pressure dropped $\geq 30 \%$ for $\geq 10 \mathrm{~s}$ with $\geq 4 \%$ desaturation drop from baseline, with $\geq 90 \%$ of the event's duration meeting the amplitude reduction criteria for hypopnea (criterion A). Sleep hypoventilation is defined by the AASM as an increase of $1.3 \mathrm{kPa}$ or more in $\mathrm{P}_{\mathrm{a}} \mathrm{CO}_{2}$ during sleep, to a value exceeding $6.7 \mathrm{kPa}$ for at least $10 \mathrm{~min}$ [22].

\section{Statistical analysis}

Sample size calculations up front showed that for $N=28$, a $\mathrm{P}_{\mathrm{tc}} \mathrm{CO}_{2}$ difference between alcohol and control sleep would be detected with $80 \%$ probability at a two-sided 0.05 significance level if the true difference was $0.25 \mathrm{kPa}$, assuming a within-patient standard deviation of $0.32 \mathrm{kPa}^{7}$

Data were assessed for normality of distribution and homogeneity of variance. No violation of the assumptions of normality, linearity, multicolinearity, and homoscedasticity was found preliminary to regression analysis.

Differences between groups with continuous, paired parametric data were analyzed with Student $T$, paired nonparametric data with Wilcoxon signed rank, independent non-parametric data with Mann-Whitney $U$, and nonparametric data in more than two groups by Kruskal-Wallis tests. Paired proportions were analyzed with McNemar chisquare test $(P$ value uncorrected) and correlations with Pearson's $r$.

Two-sided $P$ values of $\leq 0.05$ were considered significant in testing the main hypothesis, whereas a significance level of $P \leq 0.025$ was applied in the remaining analyses. All analyses were performed using IBM SPSS Statistics version 19.

\footnotetext{
${ }^{4}$ PICO50, Radiometer, Copenhagen, Denmark.

${ }^{5}$ Radiometer, Copenhagen, Denmark.

${ }^{6}$ Jaeger-Toennies, Hoechberg, Germany.

${ }^{7}$ In our previous study of 100 COPD subjects [12], the mean increase (standard deviation) in $\mathrm{P}_{\mathrm{tc}} \mathrm{CO}_{2}$ during spontaneous sleep was $0.49(0.32) \mathrm{kPa}$.
}

\section{Results}

The 9 men and 17 female (Table 1) were on average hyperinflated with impaired gas exchange and severe airway obstruction, 14 (54\%) of the 26 subjects at GOLD stages III and IV. Four subjects $(16 \%)$ had daytime hypoxemia (arterial pressures of oxygen $\left(\mathrm{P}_{\mathrm{a}} \mathrm{O}_{2}\right)<8.0 \mathrm{kPa}$ ), whereas only one had $\mathrm{P}_{\mathrm{a}} \mathrm{O}_{2}>12.0 \mathrm{kPa}$. CHRF $\left(\mathrm{P}_{\mathrm{a}} \mathrm{CO}_{2} \geq 6.3 \mathrm{kPa}\right)$ was found in four subjects, of which three used LTOT. The study group had a normal median BMI, five subjects (19\%) being underweight $(\mathrm{BMI}<21)$, whereas five were obese $(\mathrm{BMI} \geq 30)$.

As indicated in Table 2, alcohol at bedtime reduced the REM-sleep percentage of total sleep time (REM \% of TST) with a mean (SD) of 3 (7) \%, and the number of awakenings with 8 (13). However, eight subjects had an increased amount of REM sleep when influenced by alcohol (Fig. 2, groups 2 and 4).

The mean $\mathrm{P}_{\mathrm{tc}} \mathrm{CO}_{2}$ increase from supine, resting value prior to sleep $\left(\Delta \mathrm{P}_{\mathrm{tc}} \mathrm{CO}_{2}\right)$ was higher during alcohol versus control sleep (a mean (SD) increase of $0.10(0.25) \mathrm{kPa}$ ), despite nine subjects having a decrease in the mean $\Delta \mathrm{P}_{\mathrm{tc}} \mathrm{CO}_{2}$ (Fig. 2, groups 3 and 4). As shown in Table 4, alcohol-sleep changes in mean $\Delta \mathrm{P}_{\mathrm{tc}} \mathrm{CO}_{2}$ and mean $\mathrm{S}_{\mathrm{p}} \mathrm{O}_{2}$ did not correlate.

Sleep hypoventilation ( $\mathrm{SH})$ as defined by the AASM was found in two subjects ( $8 \%$ ) during control sleep and in five subjects (19\%) in alcohol sleep [22]; however, the difference was not statistically significant as one subject with $\mathrm{SH}$ in control sleep had no SH during alcohol sleep.

Ten subjects had a drop in alcohol-sleep mean $\mathrm{S}_{\mathrm{p}} \mathrm{O}_{2}$ of $>1 \%$, whereas the NREM sleep mean $\mathrm{S}_{\mathrm{p}} \mathrm{O}_{2}$ for the whole study group decreased with a mean (SD) of $0.9(2.1) \%$ $(P=.019)$. No significant change was found in REM sleep (Table 2). Interestingly, Table 2 also shows no respiratory depressant effect of alcohol during the awake periods after the initial sleep onset (N0) nor was there significant $\mathrm{N} 0$ changes in mean $\Delta \mathrm{P}_{\mathrm{tc}} \mathrm{CO}_{2}$ and mean $\mathrm{S}_{\mathrm{p}} \mathrm{O}_{2}$ when analyzing only subjects with alcohol increased sleep mean $\Delta \mathrm{P}_{\mathrm{tc}} \mathrm{CO}_{2}$ (groups 1 and 2, Fig. 2).

The median values of apneas/hypopneas and desaturations per hour of sleep (AHI and ODI, respectively) were not changed by alcohol. Despite the exclusion of diagnosed OSA prior to the study, six subjects (four males) had an AHI of $\geq 15$ per hour in control sleep. Intriguingly, Table 3 indicates that this subgroup had alcohol sleep decreases in median AHI and ODI, all with increased mean $\Delta \mathrm{P}_{\mathrm{tc}} \mathrm{CO}_{2}$ and decreased REM \% of TST.

As the three LTOT users were outliers in the data distribution of the mean $\mathrm{S}_{\mathrm{p}} \mathrm{O}_{2}$ change, partial correlation was applied, controlling for LTOT use (yes/no). Alcohol-sleep changes in the mean $\mathrm{S}_{\mathrm{p}} \mathrm{O}_{2}\left(\Delta_{\mathrm{AS}} \mathrm{S}_{\mathrm{p}} \mathrm{O}_{2}\right)$ were highly correlated to daytime $\mathrm{P}_{\mathrm{a}} \mathrm{O}_{2}$ and inversely to $\mathrm{P}_{\mathrm{a}} \mathrm{CO}_{2}$ (Table 4). However, this was not the case regarding the alcohol-sleep changes in the mean $\Delta \mathrm{P}_{\mathrm{tc}} \mathrm{CO}_{2}$ nor did hypoventilation during alcohol sleep correlate to spirometry or demographic data. 
Table 1 Study population

\begin{tabular}{ll}
\hline & $N=26$ \\
& Median (IQR) \\
\hline Demographic data & \\
Gender female & $17(65)^{\mathrm{a}}$ \\
Age, years & $65.5(14.0)$ \\
BMI, kg/m ${ }^{2}$ & $25.0(6.5)$ \\
Smoking habit & \\
Pack years & $30.4(22.4)$ \\
Current smoker & $4(15)^{\mathrm{a}}$ \\
Medication & \\
LTOT & $3(12)^{\mathrm{a}}$ \\
SABA/LABA & $24(92)^{\mathrm{a}}$ \\
Statin & $4(15)^{\mathrm{a}}$ \\
ACE/AII & $3(12)^{\mathrm{a}}$ \\
Thiazide & $3(12)^{\mathrm{a}}$ \\
ASA & $3(12)^{\mathrm{a}}$ \\
Spirometry & \\
FVC, \% of pred & $81.0(35.3)$ \\
FEV1, \% pred & $40.5(30.3)$ \\
FEV1/FVC, ratio & $0.46(0.21)$ \\
DLCO ${ }^{1}$, mmol/min/kPa & $3.92(2.49)$ \\
RV/TLC ${ }^{2}$, ratio & $0.56(0.20)$ \\
Clinical data & \\
CAT, score & $18(7)$ \\
MMRC, score & $2.0(1.0)$ \\
6-MWD, meter & $420(205)$ \\
$\mathrm{B}_{\mathrm{a}} \mathrm{O}_{2}, \mathrm{kPa}$ & $2.0(4.0)$ \\
$\mathrm{P}_{\mathrm{a}} \mathrm{CO} \mathrm{O}_{2}, \mathrm{kPa}$ & \\
$\mathrm{S}_{2}, \%$ & \\
\hline
\end{tabular}

$I Q R$ inter quartile range, $B M I$ body mass index, $L T O T$ long-term oxygen therapy, $S A B A / L A B A$ short- and/or long-acting beta-2 receptor agonist, $A C E / A I I$ angiotensin converting enzyme and/or angiotensin II antagonist, Thiazide hydrochlorothiazide, $A S A$ acetylic salicylic acid, $F V C \%$ of pred forced vital capacity as percent of predicted value, FEV1\% of pred forced expiratory volume first second as percent of predicted value, $D L C O$ diffusing capacity of the lung for carbon monoxide, $R V$ residual volume, $T L C$ total lung capacity, CAT COPD assessment test, MMRC modified medical research council questionnaire, 6-MWD 6 min walking distance, $B O D E \mathrm{BMI} /$ obstruction/dyspnea/exercise capacity, $P_{a} O_{2}$ arterial pressure of oxygen, $\mathrm{P}_{a} \mathrm{CO}_{2}$ arterial pressure of carbon dioxide, $\mathrm{S}_{a} \mathrm{O}_{2}$ arterial oxygen saturation,. Alcohol parts per thousand measured by breath analysis immediately prior to sleep

${ }^{\mathrm{a}} N$ (\% of study subjects), instead of median (IQR)

${ }^{1} N=22$, four missing from DLCO because of insufficient vital capacity or because they could not hold their breath for $10 \mathrm{~s}$

${ }^{2} N=24$, two missing from body plethysmography because of claustrophobia

${ }^{3} N=25$, one missing from 6-MWD, reason unknown
Table 2 Control versus alcohol-influenced sleep

\begin{tabular}{|c|c|c|c|}
\hline$N=26$ & $\begin{array}{l}\text { Control sleep } \\
\text { Median (IQR) }\end{array}$ & $\begin{array}{l}\text { Alcohol sleep } \\
\text { Median (IQR) }\end{array}$ & $P$ value \\
\hline \multicolumn{4}{|l|}{ Sleep architecture } \\
\hline TST, min & $354.0(65.3)$ & $354.0(62.5)$ & 0.501 \\
\hline REM \% of TST & $25(8)$ & $20(9)$ & 0.020 \\
\hline NREM $\%$ of TST & $75(8)$ & $80(9)$ & 0.020 \\
\hline WASO, min & $45.7(74.7)$ & $40.9(48.5)$ & 0.361 \\
\hline Awakenings & $28(18)$ & $19(17)$ & 0.012 \\
\hline $\mathrm{AI}$ & $15.5(10.0)$ & $18.6(10.0)$ & 0.920 \\
\hline \multicolumn{4}{|l|}{ Ventilation } \\
\hline AHI & $9.7(10.2)$ & $10.4(16.4)$ & 0.517 \\
\hline HI & $4.8(6.2)$ & $6.3(8.6)$ & 0.309 \\
\hline $\mathrm{ODI}^{\mathrm{a}}$ & $5.5(11.6)$ & $8.3(12.8)$ & 0.548 \\
\hline \multicolumn{4}{|l|}{ Mean $\mathrm{S}_{\mathrm{p}} \mathrm{O}_{2} \%$} \\
\hline N0 & $94.0(5.1)$ & $93.9(5.6)$ & 0.551 \\
\hline NREM & $93.7(4.6)$ & $93.2(5.4)$ & 0.019 \\
\hline REM & $92.5(5.4)$ & $92.8(6.4)$ & 0.258 \\
\hline Sleep & $93.4(4.7)$ & $93.2(5.7)$ & 0.058 \\
\hline \multicolumn{4}{|l|}{ Mean $\Delta \mathrm{P}_{\mathrm{tc}} \mathrm{CO}_{2} \mathrm{kPa}$} \\
\hline N0 & $0.19(0.23)$ & $0.15(0.22)$ & 0.638 \\
\hline NREM & $0.39(0.34)$ & $0.55(0.36)$ & 0.035 \\
\hline REM & $0.67(0.46)$ & $0.67(0.42)$ & 0.082 \\
\hline Sleep & $0.49(0.35)$ & $0.58(0.36)$ & 0.047 \\
\hline \multicolumn{4}{|l|}{ Sleep hypoventilation } \\
\hline $\mathrm{SH}^{\mathrm{b}}$ & $8(27)$ & $19(40)$ & 0.179 \\
\hline
\end{tabular}

TST total sleep time, REM rapid eye movement sleep, NREM non-REM sleep, WASO wake after sleep onset, Awakenings number of awakenings after sleep onset, $A I$ number of arousals per hour (arousal index), $A H I$ number of apneas/hypopneas per hour (apnea/hypopnea index), HI number of hypopneas per hour (hypopnea index), $O D I$ number of oxygen desaturations per hour (oxygen desaturation index), $S_{p} O_{2}$ oxyhemoglobin saturation by pulse oximetry, $N 0$ awake after initial sleep onset, Sleep= $\mathrm{NREM}+\mathrm{REM}, \Delta P_{t c} \mathrm{CO}_{2}$ carbon dioxide pressure increase from supine, resting value prior to sleep, $S H$ sleep hypoventilation defined by the American Academy of Sleep Medicine as an increase of $1.3 \mathrm{kPa}$ or more in $\mathrm{P}_{\mathrm{a}} \mathrm{CO}_{2}$ during sleep, to a value exceeding $6.7 \mathrm{kPa}$ for at least $10 \mathrm{~min}$

${ }^{\mathrm{a}} N=25$, one missing because of defect finger probe

b Percent of "Yes" within group (SD), instead of median (IQR)s

Finally, hierarchical multiple regressions were performed to determine whether the $\Delta_{\mathrm{AS}} \mathrm{S}_{\mathrm{p}} \mathrm{O}_{2}$ could be explained by daytime COPD characteristics. $\mathrm{P}_{\mathrm{a}} \mathrm{O}_{2}$ and $\mathrm{P}_{\mathrm{a}} \mathrm{CO}_{2}$ were entered at step 1, explaining $34 \%$ of the variance in $\Delta_{\mathrm{AS}} \mathrm{S}_{\mathrm{p}} \mathrm{O}_{2}$. After the entry of LTOT (yes/no) at step 2 , the total variance explained by the model was $49 \%,(F(3,22)=7.09, P=0.002)$. Thus, LTOT (yes/no) explained an additional $15 \%$ of the variance in the $\Delta_{\mathrm{AS}} \mathrm{S}_{\mathrm{p}} \mathrm{O}_{2}$ after controlling for $\mathrm{P}_{\mathrm{a}} \mathrm{O}_{2}$ and $\mathrm{P}_{\mathrm{a}} \mathrm{CO}_{2}\left(R^{2}\right.$ change $=0.015, F$ change $(1,22)=6.48, P=0.018)$. In the full model, using LTOT recorded the highest beta value $(0.70$, $P<.018)$, over $\mathrm{P}_{\mathrm{a}} \mathrm{CO}_{2}(-0.59, P<0.031)$, whereas $\mathrm{P}_{\mathrm{a}} \mathrm{O}_{2}$ did not make a unique contribution $(0.31, P=0.116)$. 


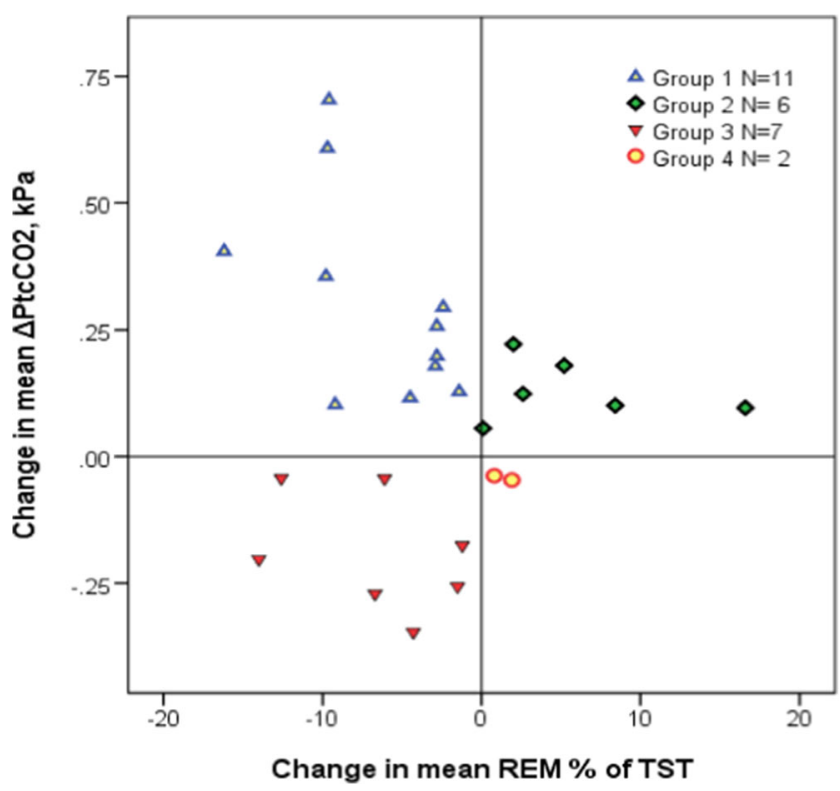

Fig. 2 Alcohol-induced changes in mean $\Delta \mathrm{P}_{\mathrm{tc}} \mathrm{CO}_{2}$ versus changes in REM-sleep percentage of TST. Each subject $(N=26)$ is represented by a colored figure according to group (legend in panel). Mean $\mathrm{P}_{\mathrm{tc}} \mathrm{CO}_{2}$ in group 1 (median (IQR) $0.26(0.28) \mathrm{kPa}$ ) differed significantly from group $3(-0.20(0.23) \mathrm{kPa}, P<0.0005)$, but not from group $2(0.11(0.10) \mathrm{kPa}$, $P=0.027$ ). The change in REM percentage of TST was significantly different between groups 1 and 2 (median $(\mathrm{IQR})=-4.5$ (6.9) \% versus $3.9(8.9) \%, P=0.001)$. Change in mean $\Delta P_{t c} C_{2}$ is the difference in the mean increase in transcutaneous carbon dioxide pressure between alcohol and control sleep. Change in mean REM \% of TST is the difference in the mean rapid eye movement sleep percent of total sleep time between alcohol and control sleep

Table 3 Alcohol-induced sleep changes in overlap subjects

\begin{tabular}{llll}
\hline$N=6$ (four male) & $\begin{array}{l}\text { Control sleep } \\
\text { Median (IQR) }\end{array}$ & $\begin{array}{l}\text { Alcohol sleep } \\
\text { Median (IQR) }\end{array}$ & $P$ value \\
\hline REM \% of TST & $25(12)$ & $21(15)$ & 0.028 \\
NREM mean $\Delta \mathrm{P}_{\mathrm{tc}} \mathrm{CO}_{2}, \mathrm{kPa}$ & $0.48(0.39)$ & $0.68(0.27)$ & 0.028 \\
REM mean $\Delta \mathrm{P}_{\mathrm{tc}} \mathrm{CO}_{2}, \mathrm{kPa}$ & $0.64(0.63)$ & $0.91(0.35)$ & 0.028 \\
Sleep mean $\Delta \mathrm{P}_{\mathrm{tc}} \mathrm{CO}_{2}, \mathrm{kPa}$ & $0.51(0.46)$ & $0.75(0.28)$ & 0.028 \\
Sleep mean $\mathrm{S}_{\mathrm{p}} \mathrm{O}_{2}, \%$ & $93.3(3.8)$ & $93.2(6.5)$ & 0.075 \\
ODI & $32(28)$ & $24(22)$ & 0.028 \\
AHI & $39(40)$ & $26(22)$ & 0.046 \\
REM AHI & $49(43)$ & $36(28)$ & 0.075 \\
NREM AHI & $31(46)$ & $30(23)$ & 0.116 \\
\hline
\end{tabular}

As no record of daytime sleepiness was available, overlap was defined as having at least 15 apneas/hypopneas per hour of sleep in subjects with chronic obstructive pulmonary disease

NREM mean $\triangle P_{t c} \mathrm{CO}_{2}$ mean pressure of transcutaneous carbon dioxide in non-rapid eye movement sleep, $\mathrm{REM}$ mean $\Delta \mathrm{P}_{t c} \mathrm{CO}_{2}$ mean pressure of transcutaneous carbon dioxide in rapid eye movement sleep, Sleep mean $\Delta P_{t c} C_{2}$ mean pressure of transcutaneous carbon dioxide in REM and NREM sleep, Sleep mean $\mathrm{S}_{p} \mathrm{O}_{2}$ mean oxyhemoglobin saturation during sleep measured by pulse oximetry, REM\% of TST REM-sleep percentage of total sleep time, $A H I$ number of apneas/hypopneas per hour of sleep, REM AHI AHI during REM sleep, NREM AHI AHI during NREM sleep

\section{Discussion}

When stable COPD subjects ( $2 / 3$ female) are given a moderate dose of alcohol immediately prior to sleep, we find a very modest sleep hypoventilation as a group mean increase in $\mathrm{P}_{\mathrm{tc}} \mathrm{CO}_{2}$ of about $0.1 \mathrm{kPa}$ and a decrease in $\mathrm{S}_{\mathrm{p}} \mathrm{O}_{2}$ of less than $1 \%$. This hypoventilation is not detectable when subjects are awake after the initial sleep onset. The mean REM \% of TST is decreased in alcohol sleep. A novel finding is subgroups showing opposite characteristics as slight hyperventilation with decreased amount of REM sleep and hypoventilation with increased REM percentage of TST. AHI and ODI are not significantly increased by alcohol; however, in overlap subjects (AHI $\geq 15 / \mathrm{h}$ ), AHI and ODI are lower. Alcohol-sleep change in $\mathrm{S}_{\mathrm{p}} \mathrm{O}_{2}$, but not $\mathrm{P}_{\mathrm{tc}} \mathrm{CO}_{2}$, is associated to daytime blood gases, and a model with LTOT, $\mathrm{P}_{\mathrm{a}} \mathrm{CO}_{2}$, and $\mathrm{P}_{\mathrm{a}} \mathrm{O}_{2}$ can explain about half of the variation in alcohol sleep change in $\mathrm{S}_{\mathrm{p}} \mathrm{O}_{2}$.

In a much referred study from 1967, Yules et al. gave $1 \mathrm{~g}$ of ethanol $/ \mathrm{kg}$ body weight to four male graduate students $4 \mathrm{~h}$ prior to sleep and found that the REM-sleep time reduced as a mean for the group; however, one subject showed no change in REM-sleep time [16]. Later, Easton et al. gave five COPD subjects $0.78 \mathrm{~g}$ of alcohol $/ \mathrm{kg}$ bodyweight immediately prior to sleep and found a mean TST decrease of $19 \%$, a REM-sleep percentage of TST decrease by $12 \%$ and a mean drop in $\mathrm{S}_{\mathrm{p}} \mathrm{O}_{2}$ of about $3 \%$ [17]. In 2007, Brander et al. studied nine males with advanced COPD using $0.5 \mathrm{~g}$ of alcohol $/ \mathrm{kg}$ bodyweight albeit taken earlier in the evening, they did not record PSG but found only a trivial decrease in $\mathrm{S}_{\mathrm{p}} \mathrm{O}_{2}(<1 \%)$ during the first $2 \mathrm{~h}$ of the reported sleep [23].

In the present study, we find REM \% of TST decreased as in the studies referred above, however, only in 18 (69\%) of the subjects. One possible explanation for the eight subjects showing increased REM \% of TST can be alcohol abstinence. Easton et al. found the REM \% of TST gradually increasing when giving alcohol repeatedly for several nights. Although none of our study subjects had a drinking problem (otherwise they would not have been included), some could nevertheless have used alcohol regularly before admission, and thus the abstinent state during the first week at the hospital might explain the increase in REM sleep when given alcohol. However, we find it unlikely that as many as $31 \%$ of the study subjects had an undisclosed alcohol problem, and as Yules et al. also described one subject with no change in REM-sleep time [16], hitherto unknown effects of alcohol on sleep can have caused the increased mean REM \% of TST in some of the subjects in the present study (Fig. 2).

In a previous article, we showed that $\Delta \mathrm{P}_{\mathrm{tc}} \mathrm{CO}_{2}$ increases with depth of NREM sleep in stable COPD and with the highest values recorded during REM sleep [12]. Thus, finding the REM percentage of TST being reduced in alcohol sleep, one would expect to find the mean $\Delta \mathrm{P}_{\mathrm{tc}} \mathrm{CO}_{2}$ to be decreased. Indeed, although not clinically impressive, the seven (27\%) 
Table 4 Correlation between alcohol-induced blood gas changes in sleep and study population characteristics

\begin{tabular}{|c|c|c|c|c|}
\hline \multirow[t]{2}{*}{$N=26$} & \multicolumn{2}{|c|}{$\begin{array}{l}\text { Change in mean } \\
\mathrm{S}_{\mathrm{p}} \mathrm{O}_{2}{ }^{\mathrm{a}}\end{array}$} & \multicolumn{2}{|c|}{$\begin{array}{l}\text { Change in mean } \\
\Delta \mathrm{P}_{\mathrm{tc}} \mathrm{CO}_{2}\end{array}$} \\
\hline & Pearson's $r$ & $P$ value & Pearson's $r$ & $P$ value \\
\hline \multicolumn{5}{|l|}{ Demographic data } \\
\hline Age, years & -0.11 & 0.616 & 0.02 & 0.914 \\
\hline Gender & 0.08 & 0.709 & 0.06 & 0.784 \\
\hline $\mathrm{BMI} \mathrm{kg/ \textrm {m } ^ { 2 }}$ & -0.13 & 0.543 & 0.13 & 0.516 \\
\hline \multicolumn{5}{|l|}{ Laboratory data } \\
\hline $\mathrm{P}_{\mathrm{a}} \mathrm{O}_{2}, \mathrm{kPa}$ & 0.51 & 0.009 & -0.25 & 0.227 \\
\hline $\mathrm{P}_{\mathrm{a}} \mathrm{CO}_{2}, \mathrm{kPa}$ & -0.58 & 0.002 & 0.11 & 0.604 \\
\hline $\mathrm{pH}$ & 0.37 & 0.071 & 0.05 & 0.816 \\
\hline \multicolumn{5}{|l|}{ Spirometry } \\
\hline FVC $\%$ of pred & 0.28 & 0.170 & -0.04 & 0.855 \\
\hline FEV1 $\%$ of pred & 0.32 & 0.125 & -0.03 & 0.886 \\
\hline $\mathrm{DLCO} \mathrm{mmol} / \mathrm{min} / \mathrm{kPa}^{\mathrm{b}}$ & 0.32 & 0.161 & -0.23 & 0.308 \\
\hline $\mathrm{RV} / \mathrm{TLC}$ ratio $^{\mathrm{c}}$ & -0.28 & 0.202 & 0.01 & 0.950 \\
\hline \multicolumn{5}{|l|}{ Sleep } \\
\hline $\begin{array}{l}\text { Change in REM \% of } \\
\text { TST }\end{array}$ & 0.12 & 0.554 & -0.15 & 0.454 \\
\hline Change in awakenings & -0.11 & 0.602 & 0.22 & 0.274 \\
\hline Change in mean $\mathrm{S}_{\mathrm{p}} \mathrm{O}_{2}$ & - & - & -0.30 & 0.135 \\
\hline
\end{tabular}

Change in mean $\mathrm{S}_{p} \mathrm{O}_{2}$ difference between alcohol and control sleep in the mean oxygen saturation, Change in mean $\Delta P_{t c} \mathrm{CO}_{2}$ difference between alcohol and control sleep in the mean increase from awake, supine, transcutaneous carbon dioxide pressure, $\mathrm{BMI}$ body mass index, $\mathrm{P}_{a} \mathrm{O}_{2}$ arterial pressure of oxygen, $\mathrm{P}_{a} \mathrm{CO}_{2}$ arterial pressure of carbon dioxide, $F V C \%$ of pred forced vital capacity as percent of predicted value, $F E V 1 \%$ of pred forced expiratory volume first second as percent of predicted value, $D L C O$ diffusing capacity of the lung for carbon monoxide, $R V$ residual volume, TLC total lung capacity, Change in REM \% of TST difference in the mean rapid eye movement sleep percent of total sleep time between alcohol and control sleep, Change in awakenings difference in the number of awakenings between alcohol and control sleep

${ }^{\text {a }}$ Partial correlation controlling for LTOT use is tabulated

${ }^{\mathrm{b}}$ Four missing from DLCO because of insufficient vital capacity or because they could not hold their breath for $10 \mathrm{~s}$

${ }^{\mathrm{c}}$ Two missing from body plethysmography because of claustrophobia

subjects in group 3 in Fig. 2 fit in this picture. Brief alcohol exposure is moderately bronco-dilating and increases the mucociliary motility in asthmatics [24], and thus can relieve nocturnal wheezing in reversible COPD subjects, and possibly improve gas exchange in the lungs. However, the 11 (42\%) subjects with reduced REM \% of TST and increased $\mathrm{P}_{\mathrm{tc}} \mathrm{CO}_{2}$ (group 1, Fig. 2) are more in accordance with previous findings in COPD [17]. The hypoventilation demonstrated in the present study with only two subjects ( $8 \%$ ) having a mean alcohol-sleep increase in $\Delta \mathrm{P}_{\mathrm{tc}} \mathrm{CO}_{2}>0.5 \mathrm{kPa}$ and less than half having a drop in mean $\mathrm{SpO} 2>1 \%$ was considerably less impressive than Easton et al.'s findings and more in line with the results of Brander et al.[17, 23]. One obvious explanation is the amount of alcohol and the time of ingestion related to sleep onset, as Brander et al. gave less alcohol earlier in the evening compared to Easton et al., the present study using same amount of alcohol as Brander et al., but given immediately before lights off. Thus, as REM sleep is more frequent the second half of the night when most of the alcohol is metabolized, REM-sleep hypoventilation is not significantly changed. Another explanation can be the number of study subjects; as previous studies included only up to six subjects, they could have missed the individuals having decreased $\mathrm{P}_{\mathrm{tc}} \mathrm{CO}_{2}$ during alcohol sleep.

Previous studies have shown increased numbers of apneas in alcohol-sleep in asymptomatic and in snoring males, in mild to moderate OSA-males and in male, but not in female COPD subjects $[13,25,26,14,15]$. The present study did not find AHI, HI, and ODI significantly increased by alcohol. This can partly be explained by the majority of female subjects in the present study. Also, as apneas/hypopneas are most frequent in REM sleep, occurring at low alcohol content, the reduced REM \% of TST in alcohol-sleep can result in the total AHI being unchanged. However, the subgroup of mostly men with control sleep $\mathrm{AHI} \geq 15 / \mathrm{h}$ having decreased $\mathrm{AHI}$ and ODI during alcohol sleep seems to contradict previous findings in males. All these individuals are hypoventilating, yet they have fewer apneas, and although not statistically significant, the REM-sleep AHI tends to be lower in alcohol-sleep. A reduced tidal volume with increased frequency of respiration, shorter episodes of REM-sleep, less mucus, and reduced bronchial constriction can be possible explanations.

Interestingly, no changes are found in $\Delta \mathrm{P}_{\mathrm{tc}} \mathrm{CO}_{2}$ or $\mathrm{S}_{\mathrm{p}} \mathrm{O}_{2}$ in N0 (awake after initial sleep onset), suggesting that moderate doses of alcohol has a significant effect on the central respiratory control only during sleep. This is in support of Sahn et al., who did not find significant alcohol-induced hypoventilation (neither as decreased $\mathrm{PO}_{2}$ nor increased $\mathrm{PCO}_{2}$ ) in six awake subjects with severe COPD after drinking $0.78 \mathrm{~g}$ of alcohol $/ \mathrm{kg}$ bodyweight [27].

Having COPD with daytime respiratory failure correlates with alcohol-induced sleep hypoventilation, however, only as daytime blood gases versus $\Delta_{\mathrm{AS}} \mathrm{S}_{\mathrm{p}} \mathrm{O}_{2}$, and not hypoventilation as change in mean $\Delta \mathrm{P}_{\mathrm{tc}} \mathrm{CO}_{2}$ (Table 4). As the multiple linear regressions with the variables LTOT, $\mathrm{P}_{\mathrm{a}} \mathrm{O}_{2}$, and $\mathrm{P}_{\mathrm{a}} \mathrm{CO}_{2}$ can explain only half of the decrease in $\mathrm{S}_{\mathrm{p}} \mathrm{O}_{2}$ in alcohol sleep, advice to COPD patients regarding the use of alcohol cannot be based on whether they have respiratory failure or not. Nor is the severity of COPD according to FEV1 as percentage of predicted, the transfer factor for carbon monoxide (DLCO) or the residual volume as percentage of total lung volume (RV/ TLC) highly associated with the alcohol-induced sleep hypoventilation.

This study is to our knowledge the first to explore sleep hypoventilation as both oxygen desaturation and carbon dioxide increase in moderately alcohol-intoxicated COPD 
subjects; however, it has some limitations. Many comparisons increase the risk of type 1 statistical errors (falsely rejecting the null hypothesis when in fact it is true) and although an alpha-correction was applied in interpreting the results of analyses other than the main hypothesis, the significance of the results must be viewed with this risk in mind. The openlabel design can add a placebo bias to the alcohol intervention. However, we find it less likely that ventilation during sleep is affected by the knowledge of being drunk, and the fact that blood gases were unchanged when awake after initial sleep onset indicates little placebo impact. Another limitation is the lack of a detailed, structured alcohol consumption interview, as regular alcohol ingestion, although not being considered as a drinking problem, can result in a very different sleep and breathing patterns as discussed above. Thirdly, no records were made of whether or not the study subjects were fasting at the time of alcohol ingestion. The alcohol breath test performed immediately before lights off was not considered a valid measurement of blood alcohol content (BAC) as such analyses are considered to be unreliable in COPD [28-30]; nevertheless, the breath analyses showed an unexpected high variability (Table 1). Food taken together with alcohol can delay peak BAC, possibly explaining some of this variability. If BAC correlates with $\Delta \mathrm{P}_{\mathrm{tc}} \mathrm{CO}_{2}$, fasting individuals can have peak BACs and thus high $\Delta \mathrm{P}_{\mathrm{tc}} \mathrm{CO}_{2}$, values early in the night, compared to those with their BAC peak well into the night. However, supper at the hospital was at 6:30 p.m., and we find it unlikely that many study subjects ate at a later time.

\section{Conclusion/summary}

In this study of stable COPD patients drinking a moderate dose of alcohol immediately prior to lights off, we found a very modest sleep hypoventilation as increased mean $\Delta \mathrm{P}_{\mathrm{tc}} \mathrm{CO}_{2}$, a reduced REM \% of TST, and no changes in AHI. However, this combination of hypoventilation and decreased REM-sleep time was evident in less than half of the subjects, as about one-fourth had a minor sleep hyperventilation with reduced REM \% of TST and another one-fourth was hypoventilating with an increase in REM \% of TST. Also, subjects with COPD and OSA (overlap) had lower median AHI and ODI in alcohol-sleep versus control sleep. We found an association between daytime blood gases and alcohol-sleep hypoventilation as decreased $\mathrm{S}_{\mathrm{p}} \mathrm{O}_{2}$, but not increased $\Delta \mathrm{P}_{\mathrm{tc}} \mathrm{CO}_{2}$, and a regression model with the variables LTOT-use, $\mathrm{P}_{\mathrm{a}} \mathrm{O}_{2}$, and $\mathrm{P}_{\mathrm{a}} \mathrm{CO}_{2}$ could explain $49 \%$ of the variation in alcohol sleep $\mathrm{S}_{\mathrm{p}} \mathrm{O}_{2}$ change. As the blood gas changes were minor, the clinical implication of this study is that a single, moderate, bedtime dose of alcohol seems to have only minor respiratory depressant effects on the majority of COPD subjects, and in a minority even slightly improves respiration during sleep. However, caution must be applied as the study is small, and higher doses of alcohol may result in major respiratory depressive and additional negative health effects.

Acknowledgments Financial support was received from the Norwegian ExtraFoundation for Health and Rehabilitation, LHL's Research fund, Glittreklinikken LHL helse as and the Norwegian national centre of excellence in home mechanical ventilation. Minor grants received from the Norwegian lung medicine society/Takeda Nycomed, Major Eckbo's endowments and the University of Bergen. PSG hardware and software were provided by ResMed Norway.

Conflict of interests This is not an industry supported study.

Nils Henrik Holmedahl: Has received lecture honorarium from Glaxo Smith Kline and a grant from the Norwegian Lung Medicine Society/ Takeda Nycomed.

Britt Øverland: No conflict of interest.

Ove Fondenes: No conflict of interest.

Ivar Ellingsen: No conflict of interest.

Jon Andrew Hardie: No conflict of interest.

Open Access This article is distributed under the terms of the Creative Commons Attribution License which permits any use, distribution, and reproduction in any medium, provided the original author(s) and the source are credited.

\section{References}

1. Lopez AD, Shibuya K, Rao C, Mathers CD, Hansell AL, Held LS, Schmid V, Buist S (2006/2) Chronic obstructive pulmonary disease: current burden and future projections. Eur Respir J 27(2):397-412

2. McNicholas WT, Fitzgerald MX (1984) Nocturnal deaths among patients with chronic bronchitis and emphysema. Br Med J (Clin Res Ed) 289(6449):878

3. Costello R, Deegan P, Fitzpatrick M, McNicholas WT (1997/3) Reversible hypercapnia in chronic obstructive pulmonary disease: a distinct pattern of respiratory failure with a favorable prognosis. Am J Med 102(3):239-244

4. Lebowitz MD (1981) Respiratory symptoms and disease related to alcohol consumption. Am Rev Respir Dis 123(1):16-19

5. Lange P, Groth S, Mortensen J, Appleyard M, Nyboe J, Jensen G, Schnohr P (1988) Pulmonary function is influenced by heavy alcohol consumption. Am Rev Respir Dis 137(5):1119-1123. doi:10.1164/ ajrccm/137.5.1119

6. Sisson JH, Stoner JA, Romberger DJ, Spurzem JR, Wyatt TA, Owens-Ream J, Mannino DM (2005) Alcohol intake is associated with altered pulmonary function. Alcohol 36(1):19-30. doi:10.1016/ j.alcohol.2005.05.002

7. Tabak C, Smit HA, Rasanen L, Fidanza F, Menotti A, Nissinen A, Feskens EJ, Heederik D, Kromhout D (2001) Alcohol consumption in relation to 20-year COPD mortality and pulmonary function in middle-aged men from three European countries. Epidemiology 12(2):239-245

8. Tabak C, Smit HA, Heederik D, Ocke MC, Kromhout D (2001) Diet and chronic obstructive pulmonary disease: independent beneficial effects of fruits, whole grains, and alcohol (the MORGEN study). Clin Exp Allergy 31(5):747-755

9. Sahn SA, Lakshminarayan S, Pierson DJ, Weil JV (1975) Effect of ethanol on the ventilatory responses to oxygen and carbon dioxide in man. Clin Sci Mol Med 49(1):33-38

10. O'Donoghue FJ, Catcheside PG, Ellis EE, Grunstein RR, Pierce RJ, Rowland LS, Collins ER, Rochford SE, McEvoy RD, Australian trial of Noninvasive Ventilation in Chronic Airflow Limitation i (2003) 
Sleep hypoventilation in hypercapnic chronic obstructive pulmonary disease: prevalence and associated factors. Eur Respir J 21(6): 977-984

11. Tarrega J, Anton A, Guell R, Mayos M, Samolski D, Marti S, Farrero E, Prats E, Sanchis J (2011) Predicting nocturnal hypoventilation in hypercapnic chronic obstructive pulmonary disease patients undergoing long-term oxygen therapy. Respiration 82(1):4-9. doi: $10.1159 / 000321372$

12. Holmedahl NH, Øverland B, Fondenes O, Ellingsen I, Hardie JA (2014) Sleep hypoventilation and daytime hypercapnia in stable chronic obstructive pulmonary disease. Int J COPD 9: 265-275

13. Taasan VC, Block AJ, Boysen PG, Wynne JW (1981/8) Alcohol increases sleep apnea and oxygen desaturation in asymptomatic men. Am J Med 71(2):240-245

14. Dolly FR, Block AJ (1983) Increased ventricular ectopy and sleep apnea following ethanol ingestion in COPD patients. Chest 83(3): 469-472

15. Block AJ, Hellard DW, Slayton PC (1985) Minimal effect of alcohol ingestion on breathing during the sleep of postmenopausal women. Chest 88(2):181-184

16. Yules RB, Lippman ME, Freedman DX (1967) Alcohol administration prior to sleep. The effect on EEG sleep stages. Arch Gen Psychiatry 16(1):94-97

17. Easton PA, West P, Meatherall RC, Brewster JF, Lertzman M, Kryger MH (1987) The effect of excessive ethanol ingestion on sleep in severe chronic obstructive pulmonary disease. Sleep 10(3):224-233

18. Global Initiative for Chronic Obstructive Pulmonary Disease (GOLD). Global strategy for the diagnosis, treatment, and prevention of chronic obstructive pulmonary disease. Updated 2013. Available from: http:/www.goldcopd.org/uploads/users/files/GOLD Report 2013 Feb20.pdf. Accessed 25 Feb 2014

19. American Academy of Sleep Medicine (2007) The AASM manual for the scoring of sleep and associated events. In: Iber C, Ancoli-Israel S, Chesson AL, Quan SF (eds) Rules, terminology and technical specifications. American Academy of Sleep Medicine, Westchester

20. Paton A, Saunders JB (1981) ABC of alcohol. Definitions. Br Med J (Clin Res Ed) 283(6301):1248-1250
21. Quanjer PH, Tammeling GJ, Cotes JE, Pedersen OF, Peslin R, Yernault JC (1993) Lung volumes and forced ventilatory flows. Report Working Party Standardization of Lung Function Tests, European Community for Steel and Coal. Official Statement of the European Respiratory Society. Eur Respir J Suppl 16:5-40

22. Berry RB, Budhiraja R, Gottlieb DJ, Gozal D, Iber C, Kapur VK, Marcus CL, Mehra R, Parthasarathy S, Quan SF, Redline S, Strohl KP, Davidson Ward SL, Tangredi MM, American Academy of Sleep M (2012) Rules for scoring respiratory events in sleep: update of the 2007 AASM Manual for the Scoring of Sleep and Associated Events. Deliberations of the Sleep Apnea Definitions Task Force of the American Academy of Sleep Medicine. J Clin Sleep Med JCSM Off Publ Am Acad Sleep Med 8(5):597-619. doi:10.5664/jcsm.2172

23. Brander PE, Kuitunen T, Salmi T, Partinen M (1992) Nocturnal oxygen saturation in advanced chronic obstructive pulmonary disease after a moderate dose of ethanol. Eur Respir J 5(3):308-312

24. Sisson JH (2007) Alcohol and airways function in health and disease. Alcohol 41(5):293-307. doi:10.1016/j.alcohol.2007.06.003

25. Mitler MM, Dawson A, Henriksen SJ, Sobers M, Bloom FE (1988/12) Bedtime ethanol increases resistance of upper airways and produces sleep apneas in asymptomatic snorers. Alcohol Clin Exp Res 12(6):801-805

26. Scanlan MF, Roebuck T, Little PJ, Redman JR, Naughton MT (2000/11) Effect of moderate alcohol upon obstructive sleep apnoea. Eur Respir J 16(5):909-913

27. Sahn SA, Scoggin CH, Chernow B (1979) Moderate alcohol dose and chronic obstructive pulmonary disease: not a cause of hypoventilation. Arch Intern Med 139(4):429-431

28. Russell JC, Jones RL (1983) Breath ethyl alcohol concentration and analysis in the presence of chronic obstructive pulmonary disease. Clin Biochem 16(3):182-187

29. Wilson A, Sitar DS, Molloy WD, McCarthy D (1987) Effect of age and chronic obstructive pulmonary disease on the Breathalyzer estimation of blood alcohol level. Alcohol Clin Exp Res 11(5):440-443

30. Honeybourne D, Moore AJ, Butterfield AK, Azzan L (2000) A study to investigate the ability of subjects with chronic lung diseases to provide evidential breath samples using the Lion Intoxilyzer 6000 UK breath alcohol testing device. Respir Med 94(7):684-688 